\title{
Arguments of Education of Language in Higher Education in China
}

\author{
Fangyan Xu \\ Electrical Engineering Department \\ Zhengzhou University \\ Zhengzhou, China \\ e-mail:2271595727@qq.com
}

\begin{abstract}
As one of the most important abilities for a person to live and improve himself or herself, ability of language is so significant that education of language of students has been constantly emphasized since a child began his or her study in kindergarten and primary school. However, current circumstance of Chinese education in university is contradictory to some degree to its popularity in primary school and high school. As a result, many negative consequences degrade language use abilities of Chinese students, which may bring about series of severe results to both students themselves and the whole nation. In addition, even though abundance attention on education of foreign language such as English, it is also not satisfactory in many aspects. Problems related to many aspects of education of language learning like methods and consciousness of language education are urgent and necessary to be ameliorated, which requires the joint efforts of students, teachers, educational administration and even the whole society.
\end{abstract}

Keywords-significant of language education; current situation of language education; possible measures

\section{INTRODUCTION}

Along with rapid development of society and technology, demand of graduates with high ability of language use has increased unremittingly. However, what is somewhat irony is that both many students and some universities nowadays in China do not think highly of the enhancement of abilities to use language. Although increasing attention focused on English learning among university students propels numbers of students spend much time learning English and get high scores in exams, their abilities to use English are actually hardly improved much. With respect to Chinese education, it has nearly been ignored by many university students because of neglect disinterest of relevant classes and neglect of significance of capabilities of language use. Actually, these kind of capacity is momentous to both students themselves and development of many aspects of society and even country. Therefore, it is necessary and urgent for efficient measures to be taken to change current situation and make positive difference.

\section{SINGNIFICANCE OF LANGUAGE LEARING}

Language, as one of essence of long-time development of human beings, never loses its importance in human society. Its profound influence is involved in nearly every aspects of existence and progression of human beings. It is also regarded as one of the most fundamental skills of a person. Thus, excellent aptitude of language use is significant from various perspectives.

\section{A. For students themselves}

Language is nothing but a tool to convey certain kind of information, content conquers all. Education of language use is aimed at promotion of students' comprehensive ability of language performance. With rapid life and expansive communication circle of people, the abilities of using language, such as abilities of communication and expression, become undoubtedly important for individuals. On the one hand, language is an indispensable implement for people to interact with others, on which people's existence is based. On the other hand, As far as further development of students as concerned, it is high capabilities of linguistic performance that are likely to help them outstand among peers in intensive competitions in the future. To be specific, for instance, since the basic level of using language is to make persons understood by each other, students may suffer misunderstandings from classmates or friends in their life and study with low ability of oral expression and the same circumstances are likely to occur in their future works, which probably lead to awful interpersonal relationship and failure in collaboration with others. Another example is that superb writing abilities of university students are required, since the abilities are crucial for students in accomplishing their dissertation and other assignment. The writing competences will be also demanded by many popular occupations. In brief, education of language use is considerably vital for students themselves to enhance their language competence throughout their study and work. 


\section{B. For nation and society}

A specific language is tightly relevant to culture, history and social background of the nation or country. Every lasting nation possesses its own language and those without their distinctive language tend to easily extinct. Since university students are elite of national and social development, university students play an important role not only in development of science and technology, but in inheritance of traditional culture and history, which is fully revealed in the language. The education of language for university students also helps them to comprehend the culture of their nation and country much better, which is significant in continue and development of national culture and history.

\section{For international interaction}

With high quality of foreign language education, the foreign languages can also be received and understood well, facilitating interaction between different cultures and nations. Social diversity is increased with this tendency. What's more, for the sake of progression of science and technology, mastering a foreign language is necessary for students in learning from materials with other language and communicating with foreign scholars and experts.

\section{CURRENT SITUATION OF LANGUAGE LEARNING IN HIGER EDUCATION IN CHINA}

Although everybody is clear to the importance of language in various aspects, including most teachers and students, the current situation of language education is not totally satisfactory both in Chinese and foreign language in higher education. Not everyone truly attach importance of learning and education of language.

\section{A. Current situation of Chinese education in university}

Education of collage Chinese is faced with some problems which cause decline of quality of Chinese learning whose prospect is dim and bleak.

To begin with, the low status of Chinese class in higher education is obvious. Collage Chinese is even not a compulsory class in most universities. According to conclusion of a survey refer to current circumstance of collage Chinese education, only $13 \%$ students among 1000 specimens in several comprehensive universities like Chinese classes. The proportion of students who take learning of Chinese seriously is remarkably small. The importance is more and more easily ignored by most students whose major is relatively uncorrelated with Chinese class. Even many of those who choose major which requires high abilities of using Chinese, they tend to fail to attach the importance of collage Chinese learning, holding the view that they have learned Chinese for more than twenty years and that is enough for them. Thus, the students' disinterest caused by the low status of collage Chinese in return abases its status, forming a vicious circle.
In the meantime, teaching materials can not satisfy the learning demand of those individuals who are interested in Chinese learning, they tend to find teaching materials are unpractical and useless. The contents of those materials are far away from practice and include much similar knowledge they learned in high school Chinese class, containing too many classical Chinese poetries and classical masterpieces. The effective knowledge obtained from the classes can not be applied in their study in time, leading to inefficient learning. The interest of these students about Chinese class fades with their sense of failure and disappointment. In the light of statistics, more than $50 \%$ collage students who receive the investigation are discontent with their Chinese class. Students can not acquire their promotion of abilities of using Chinese. They also seldom have chances to build up their language performance through applying their theoretical knowledge into specific practice such as assignment from teacher or participation into relevant competition.

Additionally, relatively weak faculty is also responsible for predicament of collage Chinese education. The low status of Chinese class brings about poor position of Chinese teachers. They always suffer from lack of research funds, poor treatment and limited support. Therefore, no wonder that the development of Chinese education is largely slowed down. Another deserved result is that teachers hardly be able to provide students with useful instruction and help in development of various abilities in development of various language abilities that require systematical training and practice, such as abilities of reading comprehension or language organization. Furthermore teaching consciousness of collage Chinese has fell behind fast-changing ideas and conceptions of teaching. The pedagogical tasks and teaching objectives usually fail to be achieved. Classes become dull and insipid with fixed teaching method and mode. There are conspicuous gap between students and teachers, too.

\section{B. Current situation of foreign language education in university}

With worldwide interaction becoming increasingly frequent and common, foreign language education has largely developed. The most typical example is the English. English class has become one of the most important disciplines for students whatever grade they are. English class is one kind of compulsory class in nearly every university in China and there are a large number of students spending much time learning English. There are also an incredible number of tutorial classes focusing on English learning. The requirement of grades of English test is strict in nearly any job hunting and ability of using English is regarded as a kind of crucial capability to judge a person. However, enthusiasm of learning English can not conceal serious problems of English education in university. It is fact that majority of collage students regard learning English as agony. English education also does not avoid being inefficient successfully. 
On the one hand, due to huge difference between culture and culture of British, education which is pay too much attention on imparting knowledge does not work well. It is stress on improving students' understanding of culture on which language is based before passing on specific knowledge that is able to achieve effective education. Nowadays, other than few of collage students who realize this problem, the rest tend to make their earnest effects to expand their vocabulary and recite the rules of grammar without understanding the background and origin of English. What is one of the most agonizing problems for them is that those new words are too hard to be remembered and are forgotten so easily that keeping thousands of new words in one's becoming an insuperable difficulty. No wonder that those ones suffer great pain during learning of English and even some of them finally give up. Thus, the results of English education and various official English tests are not concord with original intention of education of English. In common cases that there are still considerable amount of those qualified graduate who fail to write English report and article can be received by English native researchers and communicate with foreign counterparts and scholars.

On the other hand, since new information can be readily forgotten without timely review and use, the knowledge from English class is hardly combined with students' practical experience, whose result is difficulty and affliction undergone by most collage students in learning English. It is usual for collage students that they find it difficult to improve their language abilities of English though they have no trouble understanding in English classes and get satisfactory grade in final exams. The efforts of students and teachers devoted into English learning become worthless without effective review and use of new knowledge from classes.

\section{Comparison between Chinese education and education of foreign language}

According to statements above, it is a sharp contrast between upsurge of foreign language learning and recession of learning of Chinese though Chinese is native language. The importance of English learning has largely outweighed the significance of Chinese learning from perspective of most collage students. Too much people's attention is concentrated on questions about how to learning English. The results are stasis of improvement of collage students' language abilities and neglect of development and flourish of mother language and traditional cultures. This tendency is transferring into more and more fields and aspects of people's life. In high school and primary school, the stress of learning English is revealed that the content of English class is increasingly difficult and the age of children who begin to study English is much earlier than before.

\section{POSSIBLE MEASURES TOOK TO SOLVE THE PROBLEMS}

The purpose of language education is nothing but the abilities of communication and understanding between people use the same language. It is almost impossible for a foreigner to fully grasp a language as well as native speakers because of unavoidable differences between different culture and history. In this view, learning of foreign language is aimed at grasp a kind of new language. Therefore, foreign language learning can never outweigh learning of native language.

Learning of Chinese and foreign language meet with similar problems with respect to lack of effective teaching and learning method. Besides, differences are waiting to be made in the attitude and emphasis of both students and universities towards learning of native language and foreign ones. The ability of language is not a crucial factor but only a aspect of judging a person. Some experts try their best to give warning of current situation and serious consequence of the unbalance between English learning and Chinese learning. There are also official actions have been taken to improve this phenomenon. But the effect is not obvious because of absent of students and teachers in these transformation actions.

\section{A. For collage students}

For one thing, it is impending and necessary for collage students to change their consciousness and attitude toward learning of mother language and foreign language. As the future of the nation and country, development of collage students is vital to the continue and prosperity. Collage students should not be only obsessed with meeting the requirement of their ideal job and unquestioningly pursue high grades in order to seek for socalled individual success in the future. The essential purpose of learning is to enjoy self-improvement and to be cultivated. Attention and enthusiasm of learning language should be paid on enhance the series abilities of using language including abilities of writing, reading comprehension, making speech, communicating with others and etc. Their time of learning language ought to be spent on their learning of mother language which is most useful and familiar. There are substantial connections and similarities between different languages and the abilities of using one kind of language are also able to be applied to another one.

For another, effective practices and usage of knowledge and skills learned from class and daily study are indispensable. Learning of Collage students lays emphasis on improvement of practical skills and capacities. However ingenious writing skills have nothing to do with one's progression of writing capacity without enough exercises and applications. Excellent reading ability can only derive from considerably amount of training and practices. thus collage students should reinforce the connection of learning and using.

\section{B. For faculty and university}

In the meantime, valid teachers' efforts need all-round support by University and educational administration. Plenty funds should be offered prop research of teaching awareness and methods, the treatment of language class also should be bettered in order to incite teachers' devotion to work with all their heart, which is extremely beneficial to rise status of Chinese teachers. 
Even some advanced teaching devices and teaching mode should be applied, such as online course and supervision, to facilitate communication between students and teachers and make study more convenient . Formal English test such as CET4 and CET-6 have been experience transformation, gradually becoming more pragmatic. More practical chances should be offered by educational administration which are aimed to promote collage students' ability of language use, such as official competitions of oration and writing. Proper instruction of learning traditional culture and history can also be helpful for amelioration of collage Chinese education.

\section{For society and public}

Media and public should notice the detrimental consequence of overbalance of English learning and extremely deficiency of Chinese teaching. Some change should come about in public opinion of importance of English grades. As stated above, language ability only refers to one aspect of one's comprehensive competence. Employers change their overstatement of value the abilities of foreign language into proper judgment of foreign language competence, and even set up requirement of level of using Chinese. After all, the majority employees use Chinese most frequently in their work.

Public's too heavy attention focused on foreign language learning need to be assuaged in order to balance the asymmetry of Chinese education and foreign language education. Parents, for instance, probably should provide their kids with abundance of freedom in language learning since they were little and consciously encourage their interest of traditional Chinese culture or cultures of other language. Consequently, these kids may avoid suffering inefficiency of language learning like many collage students today. Ability of foreign language is undeniably important, but inordinate emphasis tend to turn out abnormal craze out of reasonable control.

\section{CONCLUSION}

With tendency of peace and development, inheritance of culture and history is of unprecedented significance to the whole nation and country. Language education, as one of the most momentous part of culture continues, has become a central part of education. As a consequence, Chinese language education should receive plenty attention and support. Although ability of foreign language is undeniably important, inordinate emphasis tends to turn out exceeding craze out of reasonable control.
Both the current education of Chinese and foreign language have conspicuous problems and drawbacks. The abnormal unbalance of indifference of learning native language and zealotry of foreign language learning is severe. Overemphasis of foreign language learning push most collage students suffer a lot in their study because of lack of effective ways of learning and instructions from teachers. Deficiency of requirement on Chinese learning brings about majority of students' disinterests in learning Chinese. In addition, poor status of Chinese education in Higher Education perplexes Chinese teachers and both Chinese teachers, English teachers and other people involved in language education are experiencing difficulty of improving teaching quality, developing efficient teaching methods and arousing students' interest toward their classes.

More and more people have set out to make changes after noticing this phenomenon. However, the accomplishment of overcoming those ingrained problems does not require efforts of a single person or organization but at the expense of endeavor of all the collage students, collage teachers and even the whole society and government. I am strongly convinced that these efforts are absolutely worthwhile. Though is tough and chronic, the transformation of language education will be finish and finally benefit everyone of our nation.

\section{ACKNOWLEDGMENT}

I would like to express my heartfelt thanks to many people whose help provide me with much motivation and instructions in my academic studies over the past years.

My deepest gratitude to my family, thanks for their support, patience, encouragement. I also want to convey my thanks to schoolmates and classmates with whom I discuss and communicate about many issues and questions about my research. And thanks to my dear friends who have given their great help to me in my research.

\section{REFERENCES}

[1] Rresurvey of current situation of collage Chinese Liu Wendong, age of university, 2006.9

[2] strategy and importance of culture education in collage English, Zhenghong,

[3] Thinking and suggestion of current situation of collage English in China, Xue Yanyan, China science and technology information, 2010

[4] .Measures and suggestions of teaching in collage English, Wan Yongken, Journal of YuXi Techers' Collage, 2003.8 